\title{
Elementos históricos e filosóficos para a crítica da epidemiologia*
}

\section{Historical and Philosophical bases for a criticism of epidemiology}

\author{
José Ricardo de C. M. Ayres"*
}

\begin{abstract}
AYRES, J.R. de C.M. Elementos históricos e filosóficos para a crítica da epidemiologia. Rev. Saúde Pública, 27: 135-44, 1993. Objetivou-se identificar as bases históricas e filosóficas da epidemiologia, a fim de enriquecer a reflexão sobre a inserção dessa ciência no conjunto das práticas de saúde. Utilizando-se informações historiográficas extraídas de textos consagrados na literatura especializada, e buscando-se subsídios téricos e metodológicos na produção da epistemologia histórica francesa, procede-se a uma aproximação epistemológica apoiada ético-filosoficamente na crítica da razão modema desenvolvida pela chamada Escola de Frankfurt. Destaca-se a noção abstrata de "meio" na tradução teórica do "espaço público da saúde" como a base contraditória da conformação instrumental do conhecimento epidemiológico. Com base nesta noção ampliou-se, de forma progressiva, a possibilidade de conhecimento e intervenção sobre os fenômenos sanitários, mas, ao mesmo tempo, limitou-se a objetivação do caráter propriamente público desses fenômenos.
\end{abstract}

Descritores: Epidemiologia, história. Métodos epidemiológicos. Filosofia. Medicina Social.

\section{Introduçáo}

A epidemiologia tem vivido, nos últimos anos, ricos questionamentos acerca de suas bases epistemológicas, isto $\varepsilon$, seus pressupostos teórico-filosóficos, sua metodologia científica, suas técnicas de investigação, entre outros. Adjetivos como epidemiologia "clínica", epidemiologia "social", epidemiologia "crítica" indicam a existência de compreensões diversas já com relação à própria identidade científica deste saber. Chega-se, em certos casos, à suspeição acerca da cientificidade mesma da epidemiologia seria ela uma ciência, com seu objeto próprio, ou apenas um método científico, uma forma sistemática de investigar objetos definidos por outras ciências?

* Apresentado ao II Congresso Brasileiro de Epidemiolo. gia, Belo Horizonte, 1992; baseado na Dissertação de Mestrado "A epidemiologia e o projeto emancipador nas práticas de saúde: a crítica da razão instrumental na constituição historica da ciência epidemiologica", 1991, apresentada à Faculdade de Medicina da Universidade de São Paulo.

* Centro de Saúde Escola Samuel B. Pessoa (C.S.Escola do Butantã), Departamento de Medicina Preventiva da FMUSP - Sâo Paulo, SP - Brasil.

Separatas/Reprints: J.R. de C.M. Ayres - Av. Dr. Vital Brasil, 1490 - Butantã - 05503-000 - São Paulo, SP - Brasil.

Edição subvencionada pela FAPESP. Processo Medicina 93/ 0208-5.
Formando o substrato desses questionamentos mais amplos, uma série de aspectos particulares ocupa epidemiologistas e profissionais afins: quais os modelos determinísticos mais adequados à explicação de fenômenos de natureza epidemiológica, quais os critérios apropriados de validação do conhecimento, quais os melhores desenhos de pesquisa, quais as técnicas mais eficazes para a apreensão da realidade epidemiológica?

As questões acima poderiam parecer dizer respeito apenas à rotina de trabalho de um círculo específico de cientistas, sendo de interesse metodológico em senso estrito, mas a verdade é que, por trás da aparência exclusivamente operacional dessas questões, estão aspectos mais amplos da vida social.

De fato, é possivel relacionar a pluralidade e as tensões que vêm marcando as diversas proposições no debate travado hoje na epidemiologia com profundas contradições geradas em esferas mais abrangentes das práticas sociais, ainda que, algumas vezes, tome-se difícil reconhecer estas contradições nos termos em que são retraduzidas no plano epistemológico. Grande parte dos diferentes problemas e respostas que vêm sendo formulados ao longo do desenvolvimento da epidemiologia como ciência pode ser explicada pelos sucessos e fracassos, consensos e conflitos, chances e obstáculos na realização de necessidades de saúde dos diversos indivíduos e grupos humanos vivendo em sociedade.

É a partir desta perspectiva que se entende aqui a relevância e o vigor do debate episte- 
mológico na epidemiologia. É esta perspectiva que, por isso mesmo, será adotada nesta reflexão.

A concepção que juśtifica e fundamenta o presente trabalho é a de que os impasses epistemológicos, acima indicados, são amplamente determinados pela complexidade e pelo caráter contraditório das necessidades sociais (individuais e coletivas) que foram constituindo, historicamente, a saúde pública como campo de práticas. Na mesma proporção e sentido em que se vão tornando fundamentais para a vida humana na sociedade moderna, tais necessidades determinam, de formas menos ou mais mediadas, as diversas proposiçסes abstratas que caracterizam a epidemiologia como ciência (e, enquanto tal, como, também ela, uma esfera de necessidades e práticas do campo da saúde pública).

Será, portanto, de grande interesse examinar os dilemas epistemológicos da epidemiologia sem a habitual restrição à dimensão estritamente lógico-formal. Abordar as questões teóricometodológicas da epidemiologia no contexto mais abrangente de suas articulaçð̋es práticas pode mostrar-se um recurso necessário para a superação da "crise de identidade" apontada no início deste texto. Só o resgate da identidade prática da epidemiologia parece, hoje, capaz de levá-la a superar o aparente paradoxo de ver obscurecer-se sua identidade cientifica e esvaziar-se a organicidade de seu corpo teórico na mesma velocidade em que se multiplicam e sofisticam seus recursos técnicos de investigação e análise.

A partir do posicionamento ético favorável ao adensamento teórico de uma "ciência da saúde pública", e somando esforços ao compromisso tecnopolítico da medicina social com a sua construção efetiva, torna-se objetivo central do presente trabalho a investigação da constituição histórica das bases empíricas e racionais de um campo propriamente epidemiológico de objetividade científica. Procurar-se-á resgatar as raízes das feiçōes atuais da epidemiologia e de suas correspondentes contradiçőes. Para isso, serão detectadas as inflexōes mais importantes na história epistemológica de um saber de corte científico acerca dos fenômenos coletivos da saúde, buscando relacioná-làs às necessidades de saúde pública, nos contextos sociopolíticos em que ocorreram. Espera-se, desta maneira, contribuir para a expansão do horizonte crítico das diversas proposições teóricas e metodológicas de construção desse saber tão estratégico para a emancipação igualitária dos homens no campo sanitário.

\section{Razáo tecnológlca e o espaço público da saúde}

Apesar da historiografia tradicional ir, muitas vezes, buscar as origens da epidemiologia na Antigüidade Clássica, no.trabalho "Ares, águas e lugares", de Hipócrates ${ }^{28}$, não parece adequado localizar nessa obra as bases de uma objetividade propriamente epidemiológica. $O$ recurso ao quadro teórico da epistemologia histórica francesa, de Canguilhem e Foucault, deixa claro o equivoco desta genealogia clássica.

Como afirma Canguilhem ${ }^{12}$, "o passado de uma ciência não se confunde com essa mesma ciência no seu passado". Assim, se a obra de Hipócrates está, efetivamente, entre as primeiras referências à relação de aspectos externos ao organismo individual com fenômenos de saúde e doença, a análise dos conteúdos conceituais e da estrutura discursiva da mesma aponta descontinuidades importantes com a construção teórica que caracteriza a epidemiologia. De tal magnitude e relevância são essas descontinuidades que não se justifica, senão por razões cuja especulação foge aos propósitos do presente trabalho, buscar na ciência e na conjuntura hipocráticas as bases da construção do campo objetivo da epidemiologia.

A obra de Hipócrates ${ }^{28}$ caracteriza-se, sinteticamente, por três aspectos básicos: 1) os elementos "externos" ao organismo humano são compreendidos como portadores de qualidades essenciais; 2 ) as qualidades dos elementos externos são depreendidas "a priori" segundo processos dedutivos abstratos; 3) o conhecimento dos mesmos tem como finalidade a compreensão mais adequada da singularidade de cada doente a ser tratado pelo médico grego.

Essas características do conhecimento hipocrático e de sua orientação prática deixam claras as descontinuidades acima referidas.

$O$ objeto epidemiológico, tal como concebido hoje, está longe de ser apreendido por intermédio de qualidades essenciais: cada fenômeno epidemiológico tem seu significado determinado pelas condições objetivas de sua apreensão, e só nessas condiçð̃es adquire objetividade. Sua caracterização, por outro lado, não procede de mecanismos dedutivos abstratos, mas é configurada a partir de dados indutivamente construídos, isto é, de conhecimentos empíricos acumulados pela experiência sensível, mesmo quando dedutivamente intuídos. Por fim, ainda que possa concorrer para ações de caráter individual, a inferência epidemiológica rcfere-se substantivamente a coletivos, a grupos de indivíduos, não podendo, senão à força de artifícios nem sempre legítimos, ser 
tomada como expressão objetiva de condições humanas singulares.

Um objeto de conhecimento assim configurado so tem, verdadeiramente, condiçøes empíricas e lógicas para plasmar-se muito tempo depois da Antigüidade Clássica. Como questão prática e como construção abstrata, o objeto da epidemiologia é produto da Modernidade.

Nesse sentido, dois movimentos precisam ser considerados quando se trata de compreender 0 nascimento da ciência epidemiológica. De um lado, está o processo de emancipaçāo da dimensäo tecnológica da razāo $0^{27,37} \mathrm{e}$, de outro lado, da emancipação dos sujeitos privados na constituição do espaço público da sociedade ${ }^{4,26,44}$, sendo, um e outro, marcos importantes, apenas analiticamente distinguíveis, do processo de emergência do período moderno na história das sociedades ocidentais.

\section{Tome-se Iniclalmente a questáo da razáo.}

Todo procedimento racional, em qualquer lugar ou tempo em que tenha sido realizado, admite sempre ser entendido como "tecnológico", uma vez que ele poderá ser compreendido como "instrumento" para a transformação produtiva da realidade, de modo a reproduzir, material e espiritualmente, o sujeito que o realiza ${ }^{24,38}$. Os vários estatutos que a razão humana se autoconferiu ao longo da história da civilização ocidental são racionalmente compreensíveis - a partir da concepção teórica aqui adotada - como parte do conjuntos de instrumentos que os homens de cada época desenvolveram para garantir sua subsistência física, para realizar suas ambições éticas, dar vazão às suas vivências estéticas, entre outros.

No entanto, na sua aptidão reflexiva, na sua autocompreensão, a razão tem interpretado essa condição de "instrumento" com conteúdos e relevância variáveis. Se hoje é possível pensar a razão como sendo fundamentalmente este instrumento, é justamente porque a razão moderna emancipou sua dimensão tecnológica, isto é, passou a privilegiar como seu atributo e sua finalidade a capacidade de interferir ativamente nas condiçð̃es de vida do homem.

O conhecimento do modo como as coisas são na realidade foi, progressivamente, substituindo a especulação sobre o que é a rcalidade das coisas, na auto-compreensão da razão moderna acerca de suas vocações mais legítimas. Conhecer e dominar os processos materiais a partir dos quais as coisas vêm a ser o que são, reproduzindo-os e aperfeiçoando-os, em alguns casos, e atenuando-os ou suprimindo-os, em outros, é o que a razão passa a entender como sua competência e função $0^{9,30,53}$.
A grande novidade da razão na Era Moderna é, portanto, a dissociação entre a possibilidade de conhecer a realidade objetiva do homem e transformá-la, e a busca das causas primárias (ou últimas) do mundo, a razão de ser de todo o universo e de cada coisa no universo. Desde Descartes, essa dimensão secular e prática da razão passou a alcançar cada vez maior autonomia, eficácia e valorização social e, conseqüentemente, maior legitimidade.

A configuração histórica de um saber substantivamerte epidemiológico começa já em pleno processo de emancipação da racionalidade tecnológica. Os trabalhos que manifestam os primeiros movimentos de "epistemologização"21 desse saber, isto é, os primeiros discursos aspirantes ao estatuto de verdade objetiva acerca do processo saúde-coença nos moldes em que a epidemiologia veio a ésenvolver, datam do século XVIII ${ }^{6,10,34}$. Nesse período, em consonância com a superação do projeto social hegemônico no modo de produção fe:Jdal pelo(s) projeto(s) de um modo de produção organizado em moldes capitalistas, já havia amilo predomínio da racionalidade tecnológica, ianto em termos sociopolíticos como em termos estr::amente epistemológicos.

A dimer.são secular da realidade e das necessidades do homem passou, então, a ser conscientemente tomada como a origem e as bases para a formulação de problemáticas e de caminhos para sua soluçãc, substituindo as motivações e os fundamentos transcendentais que sustentavam ideologicamente a antiga Ordem. $\mathrm{O}$ momento indutivo da produção da abstração teórica, por partir da experiência dos cinco sentidos materiais do homem, ganhou terreno em relação à dedução, considerada uma porta sempre aberta a "devaneios" metafísicos. Por fim, a busca da certeza quanto à validade do conhecimento não pôde mais prescindir da evidência empírica, já que o domínio da lógica não representava mais qualquer garantia de acesso às verdades do mundo. $\mathrm{A}$ propósito do conhecimento humano, Hume ${ }^{29}$ viria a afirmar de forma paradigmática: "Contém ele algum raciocínio acerca da quantidade ou do número? Não. Contém ele algum raciocínio experimental relativo à questão do fato e à existência? Não. Lançai-o às chamas, porque só pode conter sofisma e ilusão".

Com base nos corolários acima, uma série de importantes mudanças ocorreram nas relaçðes entre teoria e prática em todos os campos da atividade humana, inclusive na saúde. O nascimento da epidemiologia é uma dessas mudanças. Ele será examinado, a partir deste ponto, com o recurso ao segundo movimento acima citado: a constituição de um espaço público estruturalmente diverso daquele existente na Idade Média, um espaço de in- 
teração entre sujeitos privados politicamente emancipados.

Assim como a razão transpõe as fronteiras da Modernidade através de uma transformação estrutural de suas articulações práticas e de sua autocompreensão abstrata, também a maneira da sociedade constituir e compreender a comunidade socionatural de seus componentes vive radicais transformaçð̃es. A dimensão pública da experiência social do homem era, na Idade Média, concebida e construida através de normas e símbolos que transcendiam as necessidades e juizos de cada individuo particular, de cada sujeito social. Estes diziam respeito ao espaço privado, uma esfera de sociabilidade que atingia apenas o núcleo familiar ou, no máximo, agrupamentos societários, isto é, derivados de interesses materiais mútuos. Já a sociabilidade ampliada da esfera pública era um espaço de vivências gregárias, isto $e$, de reconhecimento, transmissão e celebração da identidade de valores espirituais, morais e culturais que amalgamava as sociedades feudais.

O espaço público, enquanto ambiente físico, instituição social ou conjunto de práticas, assumia um caráter metafísico e representativo, ou seja, derivava, aparentemente, de uma ordem divina. Era o espaço de realizar e ver realizado os papéis de cada um num grande "drama", determinado por forças externas e superiores aos homens. $O$ Príncipe, o castelo, a Igreja e as igrejas, a indumentária, o heroismo, as celebraçōes... cada aspecto da vida pública expressava e realizava simbolicamente a transcendência do homem em relação ao mundo material, legitimando os valores e normas que subjaziam às relações de poder na divisão da produção e do usofruto das riquezas da sociedade feudal.

Com o advento da Modernidade e do modo capitalista de produção, no entanto, o espaço público tem esse seu caráter representativo subsumido numa orientação de natureza secular, não mais transcendental. Os símbolos que sinalizam a dimensão pública da vida social passam a legitimar-se, nuclearmente, a partir de seu caráter funcional. Ainda, o que é muito relevante para os propósitos desta reflexão, o espaço público moderno passa a ser constituido por intermédio de uma construção contratual, isto é, substitui-se a pseudoespontaneidade da organização dos espaços de interação por soluçōes consensuais de diversas naturezas.

O estreitamento do caráter solidário da organização social da produção - a estruturação da atividade de produção com base na crescente cooperação das forças produtivas e na composição coletiva da força de trabalho - e a propriedade privada como princípio da divisão social e técnica do trabalho, foram, em poucas palavras, as bases materiais dessas transformaçōes. Elas foram condição de possibilidade ideológica e política para o sujeito privado conceber e postular que os juízos e valores relativos às suas necessidades materiais fossem fonte legítima de normas e símbolos para a esfera gregária da experiência humana.

A esfera pública moderna passa, então, a configurar-se como o espaço fisico, institucional $e$ cultural de circulação e troca, societariamente organizadas, de valores materiais e espirituais dos sujeitos privados. Quanto mais organicamente a sobrevivência material dos indivíduos se organiza em práticas coletivizadas de produção e consumo, mais rápida e profundamente se estrutura o espaço público moderno.

É a partir deste processo histórico que se torna compreensível a configuração de um saber que apreende os aspectos extra-orgânicos do processo saúde-doença como uma "condiçâo transindividual". Ou seja, só quando a razão tecnológica é chamada a conhecer condições desfavoráveis às interaçoes entre necessidades privadas socialmente legitimadas é que se desenvolve a consciência de uma dimensão da realidade de saúde que diz respeito a determinados indivíduos, não se restringe à realidade de qualquer um deles em particular, e é do interesse de todos. Só a partir dessa "mentalidade sanitária" pôde emergir uma objetividade propriamente epidemiológica.

A emergência histórica da mentalidade sanitária relaciona-se dialeticamente com mudanças em todas as esferas de saberes e práticas de saúde. $\mathrm{Na}$ esfera tradicional - a esfera dos sujeitos privados - deu origem à clínica, ou medicina moder$\mathrm{na}^{17,20}$. No mesmo movimento gerou, no que se refere à esfera pública, a higiene moderna ${ }^{5,45}$ cujos saberes constituem a matriz epistemológica da epidemiologia.

A higiene de fins do século XVIII e início do século XIX na Europa, constitui, de fato, o primeiro saber tipicamente moderno a tomar como objeto a transindividualidade do processo saúdedoença, a identificar "patologias" no "corpo" social, e a buscar a determinação das mesmas nas condições de vida dos diversos grupamentos socialmente diferenciados. Na higiene, especialmente na higicne iluminista francesa, de Villermé, Desalle, Parent-Duchatelet, entre outros, estão as raízes metodológicas, conceituais, éticas e filosoficas da epidemiologia.

É preciso ter claro que a higiene não chegou, ela própria, a configurar-se como uma ciência em moldes modernos, apesar de, às vezes, autointitular-se assim. Ela permaneceu num estágio epistemológico que pode ser melhor designado, 
seguindo Canguilhem ${ }^{12}$, como uma "ideologia científica".

Diz Canguilhem ${ }^{12}$, que uma ideologia científica é um saber a respeito de algum aspecto objetivo da existência que não elabora, enquanto tal, um modo operativo de validação de suas normas de cientificidade. Dito de outra forma, uma ideologia científica é o saber objetivo que precede uma ciência, e o que caracteriza a passagem de uma à outra forma de saber é o estabelecimento de uma normatividade interna ao conhecimento, o desenvolvimento de axiomas que garantem aos enunciados teóricos, de forma estável e simultânea, a veracidade da relação "conceito abstrato - realidade concreta" e a organicidade da relação "conceito - teoria". Através de seus axiomas, a ciência garante que fala verdades e que elas são verdades características do seu objeto.

Prende-se ao processo acima a relevância da higiene para os propósitos desta reflexão. A higiene, na condição de saber pré-científico acerca da saúde no espaço público, produziu conhecimento abundante, em quantidade e qualidade, abordando de forma ampla e profunda a dimensão social do processo saúde-doença e alcançando notável impacto prático ${ }^{1}$. Entretanto, quando a estrutura discursiva da higiene atravessou seu limiar de "formalização científica"21, reduções consideráveis foram operadas no seu campo de objetividade, o que era inevitável. É exatamente esta redução que interessa aqui destacar, pois o modo como se dá o reducionismo de uma ciência, por referência às pretensões teóricas da ideologia científica que a precede, indica a direção concretamente tomada pelo saber para a obtenção de sua legitimação como conhecimento objetivo; indica que tipo de verdades este saber se propðe a enunciar e sobre que aspectos da realidade pretende se debruçar. E o que será examinado na seqüência.

\section{A noçáo de meio e a epidemiologia como ciêncla}

Diversos elementos da conjuntura científica do nascimento da epidemiologia precisam ser considerados quando se trata de compreender o campo de objetividade que resulta de sua formalização científica. Os notórios progressos conceituais das ciências biológicas, os expressivos êxitos práticos do experimentalismo de Claude Bernard, o vultoso desenvolvimento técnico da estatística vital, o amadurecimento filosófico do empirismo científico, entre outros aspectos, ajudam a explicar as filiações teóricas e o perfil metodológico dessa ciência ${ }^{32,33,46,51}$.
Sem menosprezar a importância desses elementos na configuração da ciência epidemiológica, parece inadequado, porém, limitar aos mesmos a compreensão de sua determinação. Se, por um lado, a epidemiologia não pode ser concebida sem a concorrência desses elementos, eles são incapazes, por outro lado, de esclarecer a questão central desta reflexão: o paroxismo instrumental do conhecimento epidemiológico e a correlata "desagregação" teórica do seu corpo conceitual. Para isso, será necessário voltar a ampliar a reflexão para o cenário mais abrangente das práticas sanitárias e circunstanciar o movimento epistemológico que privilegia o conhecimento de certos aspectos da determinação da saúde no espaço público em detrimento de tantos outros apontados pela higiene.

A formalizaçăo da ciência epidemiológica, a partir da segunda metade do século XIX, dá-se no contexto da consolidação institucional da nova ordem social, conduzida sob a hegemonia políticoideológica da burguesia. As práticas e os saberes sanitários não ficaram à margem desse processo, como não poderia deixar de ser. Ao contrário, eles se fizeram instrumentos fundamentais dessa consolidação, em função de sua grande importância na reconstrução de um espaço público mais adequado à livre circulação de valores e idéias exigidas pelos novos tempos ${ }^{18}$.

Contudo, por evidenciar necessidades contraditórias nas interaçóes entre os sujeitos privados, denunciadas pelas diferentes formas e freqüências desses indivíduos adoecerem em uma mesma sociedade, a natureza estratégica desse conhecimento variou, se analisado antes ou após o fim do processo revolucionário que conduziu a burguesia ao poder.

Na sua fase científico-ideológica, correspondente ao período revolucionário da implantação da nova ordem social, o recém emancipado caráter tecnológico da razão punha-se a serviço da denúncia e superação das condiçōes desfavoráveis à saúde no espaço público, por meio da transformação radical das relações entre os diversos sujeitos sociais. Um amplo arco de forças sociais, unidos sob o léxico da "liberdade, igualdade e fraternidade", davam viabilidade política a esse projeto intelectual. Os princípios éticos do humanismo revolucionário secundarizavam a necessidade de qualquer tipo de normatividade epistemológica para a higiene, uma vez que a normatividade que deles próprios emanava agia como critério objetivo para a positividade das inferências e explicaçðes.

As exigências dessa normatividade interna não tardaram, contudo, a chegar, uma vez que, ao se consolidarem institucionalmente novas relações 
sociais, com base em novas e assimétricas estruturas de poder, o caráter inevitavelmente plural de saberes cuja positividade provinha de valores éticos tornou-se insustentável. Não se tratava mais de reconstruir as práticas sociais, mas de aperfeiçoálas, de potencializar seu caráter construtivo nos limites de balizamentos éticos comuns, fixados "a priori" pelos valores hegemônicos nas novas estruturas de poder.

O processo então vivido pelas ciências é conhecido. As constantes físicas e químicas e as regularidades matemáticas passaram a conformar a normatividade epistemológica preferencial no campo da saúde, como em todo o campo científico ${ }^{13,22,35}$.

Isto se dev à aptidão desses elementos para oferecer, ao conhecimento objetivo, critérios positivos estritamente instrumentais, autônomos em relação aos valores do sujeito que conhece. As quantidades são as formas mais abstratas de apreensão e comparação de comportamentos empíricos, possibilitando significativa independência da inferência científica em relação ao significado concreto do objeto estudado. As constantes físicas e químicas estabelecem, por sua vez, horizontes fenomênicos comuns para as mais diversas perspectivas subjetivas.

Para esse "paroxismo instrumental"27, isto é, para esta normatividade intracientífica naturalizada e quantificada, tenderam todos os processos de formalização científica a partir da segunda metade do século XIX, incluindo o da epidemiologia. Resta saber como a higiene, um saber plasmado substantivamente no plano das relações do homem com o próprio homem e com o mundo, pôde desenvolver critérios epistemológicos de validação independentes da concretude das relaçðes humanas, da pluralidade contraditória dos valores dos sujeitos privados. Como foi possível, em termos epistemológicos, passar a apreender objetivamente a dimensão social do processo saúde-doença a partir de constantes e quantidades? Esta é a questão que se impõe neste ponto da reflexão.

Examinando-se as primeiras construções teóricas tipicamente epidemiológicas, é possível identificar um elemento epistemológico fundamental para realizar, nesta ciência, o paroxismo instrumental da racionalidade científica moderna: a noção abstrata de meio. Através dela, o causalismo biologicista adentra o campo objetivo da inferência epidemiológica e estabelece, com força de dogma, normas de cientificidade desenvolvidas em esferas de objetividade estranhas à sta, no campo das ciências naturais.

Segundo Canguilhem ${ }^{15}$, o conceito de meio é formulado pela primeira vez por Newton, na física, não como produto da observação imediata, mas como uma necessidade lógica da sua mecânica. Esse conceito permitiu a Newton superar as antigas noções da física com uma mecânica baseada na interação simultaneamente recíproca e independente dos corpos. O "meio" foi, inicialmente, uma conjectura teórica derivada das evidências empíricas da nova mecânica, mas acabou por se consolidar conceitualmente como esta qualidade de "pôr em relação", especialmente quando transportado por Comte às ciências biológicas.

Funcionando como recurso conceitual para expressar a noção de exterioridade qualitativamente contínua e homogênea que relaciona círculoesfera, unidade-todo, finito-infinito, o meio se configurou na biologia como um "instrumento universal de dissolução das sínteses orgânicas individualizadas, no anonimato dos elementos e movimentos universais". Ele "desvalorizou" as qualidades que compunham o substrato concreto dos objetos que punha em relação. Configurou-se como um "sistema de relaçס̄es sem suporte"15.

A incorporação do conceito de meio no pólo clínico dos saberes da saúde dá-se, principalmente, pelas mãos de Claude Bernard. Este declara, explicitamente, a influência do conceito, tal como Comte o desenvolvera, na formulação da noção de "meio interno", um dos pilares fundamentais de sua patologia experimental ${ }^{14}$.

No pólo sanitário está ainda por ser feita a recuperação histórica da trajetória que levou a noção de meio aos contagionistas ingleses. John Stuart Mill, um dedicado estudioso de Comte, e uma espécie de "recondicionador" de sua doutrina para o empirismo inglês, parece ser a peça chave dessa transmissão, considerando sua influência nas formulaçðes científicas de John Snow, Budd, o último Farr, entre outros ${ }^{54}$.

"Sobre a maneira de transmissão da cólera" de Snow ${ }^{48}$, é o trabalho emblemático da aplicação do conceito de meio na epidemiologia.

$O$ caráter abstrato de que se reveste a transindividualidade da cólera no raciocínio de Snow fica evidente já desde a fundamentação de sua metodologia de investigação, baseada na possibilidade de associar as condições extra-orgânicas relacionadas à doença com características fisiopatológicas da mesma. De fato, todo o trabalho de Snow pode ser resumido como um minucioso e brilhante esforço de relacionamento abstrato de inúmeros elementos extra-orgânicos (que a higiene, ao longo dos anos anteriores, associara positivamente à dimensão pública da saúde) com as disfunçð̃es gastrintestinais que caracterizavam o quadro orgânico da cólera. Snow logra associar, nos moldes do causalismo mecanicista das ciências naturais, fenômenos naturais e não naturais, 
lançando mão da noção de um espaço real estranho aos corpos biológicos mas tornado conceitualmente contínuo a estes.

Esta construção tornou-se possível porque a noção de meio permitiu relacionar externo e interno através de uma mesma referência qualitativa. Através dela, os elementos externos puderam ter sua identidade objetiva restringida à condição de "interdiçâo e transmissão" da mecânica fisiopatológica do cólera.

Em uma obra posterior ${ }^{47}$, Snow explicita de forma clara este seu procedimento. Ele afirma ter partido, em sua investigação, da consubstancialidade entre os fenômenos físicoquímicos inorgânicos, ou de laboratório, e aqueles que acontecem nos seres vivos. Mesmo admitindo a especificidade dos processos vitais, o cientista inglês julgava possível apreender tais processos por meio de sua substância físicoquímica. Segundo Snow ${ }^{47}$, a vida pode ser definida como uma série de "alterações moleculares" (formas de interação entre as partículas da matéria em distâncias insensíveis) que se transmitem em todas as direções. A partir disso, conclui: "Somando-se à série de mudanças moleculares contínuas que têm por resultado a preservação do indivíduo e da espécie, há outras, ocorrendo em seres vivos, que têm uma tendência oposta; elas desviam parte da substância do indivíduo das açōes que são naturais à espécie para um outro tipo de ação, em consequiência de que essa substância é empregada na multiplicação e incremento da "materies morbi" de doenças comunicáveis - um extenso grupo de doenças, cada qual causada por algum material que, como regra geral, foi produzido no sistema de um outro indivíduo".

A referência de elementos empiricos de natureza diversa, tais como as condições de vida e os fenômenos fisiopatológicos, a um mesmo aspecto conceitual qualitativo - as mudanças moleculares transmitidas - limita a apreensão da dimensão transindividual do processo saúde-doença à relação dos elementos concretos da vida social com a positividade orgânica das supostas alteraçōes moleculares.

É, portanto, na versão contagionista que o saber epidemiológico logra transpor o umbral da formalização científica. A superação das teorias miasmáticas pelo contagionismo não é menos que a expressão do êxito deste último em construir um conhecimento objetivo cuja normatividade interna, por seu caráter instrumental, passou a prescindir da "falibilidade" e variabilidade de juízos humanos para garantir sua validade e veracidade. As noções modernas de miasma, ainda que secularmente fundadas, eram construçōes sintéticas, cuja objetividade era diretamente proporcional ao grau de particularização das características concretas de seu objeto e dos juízos de seu observador. Vide, a propósito, o trabalho de Villerme ${ }^{52}$, ou a clássica obra de Engels ${ }^{19}$ a respeito da situação da classe trabalhadora na Inglaterra. $O$ raciocínio contagionista, inversamente, retira sua eficácia do fato de abstrair ao máximo a concretude dos diversos agrupamentos humanos e os valores do cientista que os estuda.

De Snow à epidemiologia contemporânea muitas transformações ocorreram, que não cabe em nossos propósitos discutir. É importante apenas destacar que a substituição, no século $\mathrm{XX}$, do causalismo biologicista pela associação causal de natureza probabilística, ou a passagem ao paradigma de risco ${ }^{2}$, não modificou radicalmente este quadro. Ao contrário, a vocação abstracionista da associação probabilística e a sofisticação das técnicas de investigação e análise têm permitido ao conhecimento epidemiológico alcançar um instrumentalismo ainda mais acentuado. A ele podemos creditar os inúmeros sucessos e os incômodos fracassos que conduziram a epidemiologia contemporânea à "crise de identidade" em que se encontra.

\section{Consideraçóes finais}

Os êxitos positivos e negativos da epidemiologia têm sido muitos. Por um lado, expandiu-se enormemente a capacidade de conhecimento e transformação produtiva do espaço público da saúde, que aproximações metafísicas de diversas naturezas deixaram por longo tempo fora do alcance de uma intervenção mais positiva. Por outro lado, junto com a preterição dos juízos de valor e dos procedimentos sintéticos, em favor de uma racionalidade exclusivamente instrumental, restringiu-se o potencial de enriquecimento criativo e solidário de saberes e práticas relativos ao espaço público da saúde. Com o aprofundamento do seu caráter instrumental, a epidemiologia tem se tornado, progressivamente, capaz de fazer inferências cada vez mais precisas e consistentes sobre aspectos do real cuja gênese concreta conhece cada vez menos.

A consolidação de um campo de objetividade especificamente epidemiológico, apoiado num núcleo científico "duro", matematicamente fundado, permitiu à epidemiologia perfilar-se entre os saberes que legitimamente sustentam a intervenção sobre a saúde nos seus moldes modernos, interagindo mais radicalmente com os saberes que se ocupam da individualidade orgânica ${ }^{39}$. Resulta desse processo que a dimensão pública da saúde, posta em contato direto com as ciências biológicas 
da saúde, condiciona à consistência epidemiológica os saberes produzidos por estas ciências. Em suma, há como contrapartida da axiomatização naturalizadora da mentalidade sanitária, a "invasão do social"18 na estrutura disciplinar nuclear às práticas de saúde na sociedade contemporânea - a propedêutica clínica.

Se essa "invasão" tem o mérito de fecundar mutuamente os pólos individual e coletivo dos saberes sobre saúde, ela oferece, por outro lado, o risco, cada vez mais presente, de subordinar a construção da inferência epidemiológica a questões cada vez menos relativas à dimensão propriamente pública da saúde. Ou seja, a formalização do saber epidemiológico levou-o a uma dependência tão marcante de sua consistência com as regularidades orgânicas ${ }^{36,43}$ que tem se tornado cada vez mais dificil perseguir o que, ainda em Frost, era tido como um ideal para a epidemiologia: tornar-se "uma ciência indutiva, interessada não simplesmente na descrição da distribuição da doença mas igualmente ou mais na sua contextualização numa filosofia consistente" 23 .

A propósito, já foi sugerido, recentemente, que se retirasse o radical "demo" da designação da epidemiologia ${ }^{41}$, em uma lúcida, embora lamentável, constatação do afastamento desta ciência da esfera pública, onde estão suas raízes.

Alguns setores da comunidade científica vêm realizando esforços, em diversas direçðes, na tentativa de reter, nas categorias analíticas e modelos determinísticos adotados, a dimensão propriamente pública do objeto da epidemiologia. Na produção anglo-saxônica destacam-se os trabalhos de Cassel ${ }^{11}$, Susser ${ }^{49}$ e Terris $^{50}$; na França, mais recentemente, surge a produção de Goldberg $^{25}$; nos países latinos emergem as proposições profundamente críticas de Breilh $^{8}$ e Laurell ${ }^{31}$, entre outros. A presente reflexão vem, não obstante, somar elementos à convicção, que toma corpo no meio acadêmico $0^{3,7,16,40,42}$, de que há outras tarefas igualmente relevantes, hoje, para a superação do instrumentalismo do saber epidemiológico.

Parece, efetivamente, fundamental rever a estrutura axiomática que faz valorizar certos elementos científicos, preterindo outros, na construção de teorias e de mecanismos de validação da ciência epidemiológica. Não é suficiente construir novas categorias conceituais ou adotar modelos determinísticos não naturalizantes se não conseguirmos inverter, de certa forma, o movimento operado no núcleo do processo científico da epidemiologia. Nessè sentido, ao invés de reduzir a transindividualidade da doença aos mecanismos de facilitação ou interdição de fenômenos orgânicos, fazendo aí residir a identi- dade do objeto epidemiológico, é preciso adensar, por intermédio da interpretação positiva do significado das regularidades orgânicas, a consciência da identidade concreta dos sujeitos envolvidos nas diversas situaçōes sociais. Em um movimento interpretativo consequiente, a positividade da inferência epidemiológica não seria subordinada ao relacionamento abstrato daquelas situações sociais com constantes fisicoquímicas. Inversamente, estas constantes tornar-se-iam os elementos sinalizadores de situaçōes desfavoráveis à satisfação e enriquecimento das necessidades humanas.

A consolidação da identidade sanitária da epidemiologia mostra, assim, ser uma tarefa muito mais ampla que um "aperfeiçoamento" metodológico. A emancipação igualitária da pluralidade dos projetos de vida dos homens depende de uma esfera pública eticamente concebida, construída com justiça e solidariedade. A importância da epidemiologia para essa construção nos conduz ao difícil, mas necessário, desafio prático de colocar a autonomia tecnológica conquistada pela razão a serviço do gênero humano, e não o contrário.

AYRES, J.R. de C.M. [Historical and philosophical bases for a criticism of epidemiology]. Rev. Saúde Pública, 27: 135-44,1993. The historical and philosophical foundations of epidemiology are examined for the purpose of establishing objective bounds for a reflexive analysis as to the insertion of this science into today's health practices as a whole. With this in view, an epistemological approach, founded upon the Frankfurt School's criticism of modern rationality and some theoretical and methodological contributions from French School of historical epistemology, is attempted. Historical information was obiained from current specialized literature. The abstract notion of "environment" in the theoretical translation of "health's public space" is emphasized as the contradictory basis for the instrumental shaping of epidemiological knowledge. This abstract notion of environment has opened up increasing possibilities of knowledge of and practical intervention in sanitary phenomena, but has simultaneously restricted the objectivation of the properly public character of these phenomena.

Keywords: Epidemiology, history. Epidemiologic methods. Philosophy. Social medicine.

\section{Referências Bibliográficas}

1. ACKERNECHT, E. H. Hygiene in France, 1815-1848. Bull. Hist. Med., 22: 117-55, 1948.

2. ALMEIDA FILHO, N. Epidemiologia sem números: uma introdução crítica d̀ ciência epidemiológica. Rio de Janeiro, Ed.Campus, 1989. 
3. ALMEIDA FILHO, N. Paradigmas en epidemiologia. In: Congresso Brasileiro de Epidemiologia, 12. Campinas, 1990. Anais. Rio de Janeiro, ABRASCO, 1992. p. $329-46$.

4. AREINDT, H. A condiçäo humana. Rio de Janeiro. Ed. Forense-Universitária, 1981.

5. AROUCA, A.S.S. O dilema preventivista - contribuição para a compreensão e a crítica da medicina preventiva. Campinas, 1975, [Tese de Doutorado - Faculdade de Medicina da Unicamp].

6. BAKER, G. Ensayo sobre la causa del cólico endémico de Devonshire. In: Buck, C.; Llopis, A.; Nájera, E.; Tetris, M. El desafio de la epidemiologia: problemas y lecturas seleccionadas. Washington, Organización Panamericana de la Salud, 1988. p. 28-31. (OPAS Publ. Cient., 505).

7. BARATA, R.C.B. Epidemiologia: teoria e método. In: Congresso Brasileiro de Epidemiologia, 12, Campinas, 1990. Anais, Rio de Janeiro, ABRASCO, 1992. p. 216-23.

8. BREILH, J. Epidemiologia: economia, polútica e saúde. Såo Paulo, Ed. Unesp/Hucitec, 1991.

9. BURTT, E.A. As bases metafísicas da ciência maderna. Brasilia, Ed. Universidade de Brasília, 1983.

10. CASAL, G. De la afección que en esta província se llama vulgarmente mal de la rosa. In: Buck, C.; Llopis, A.; Nájera, E.; Terris, M. El desafio de la epidemiologia . problemas y lecturas seleccionadas. Washington, Organización Panamericana de la Salud, 1988 p. 25-7 (OPAS - Publ. Cient., 505).

11. CASSEL, J. Social science theory as a source of hipotheses in epidemiological research. Am. J. Public Health, 54: $1482-8,11964$.

12. CANGUILHEM, G. Ideologia e racionalidade nas ciências da vida, Lisboa, Ediçoes 70, 1977.

13. CANGUILHEM, G. O normal e o patológico. Rio de Janeiro, Ed. Forense-Universitária, 1982.

14. CANGUIIHEM, G. Auguste Comte. In: Canguilhem; G. Études d'histoire et d philosophie des sciences. Paris. Librairie Philosophique J. Vrin, 1983. p. 61-74.

15. CANGUILHEM, G. Le vivant et son milieu. In: Canguilhem, G. La connaissance de la vie. Paris, Librairie Philosophique J. Vrin, 1985. p. 129-54.

16. COSTA, D.C. Construção científica e inovação teórica um desafio para a epidemiologia. Rio de Janeiro, 1992. [mimeografado].

17. DALMASO, A.S.W. Estruturação e transformação da prática médica: estudo de algumas das características do modelo de trabalho na segunda metade do século XIX e início do século XX. São Paulo, 1991. [Dissertação de Mestrado - Faculdade de Medicina da USP].

18. DONNANGELO, M.C.F. \& PEREIRA, L. Saúde e Sociedade. São Paulo, Ed. Duas Cidades, 1976.

19. ENGELS, F. A situação da classse trabalhadora em Inglaterra. Lisboa, Ed. Presença, 1975.

20. FOUCAULT, M. O nascimento da clínica. Rio de Janeiro, Ed. Forense-Universitária, 1980.

21. FOUCAULT, M. A arqueologio do saber. Rio de Janeiro, Ed. Forense-Universitária, 1987.

22. FOUCAULT, M. As palavrsa e as coisas: uma arqueolo. gia das ciências humanas. São Paulo, Ed. Martins Fontes, 1990.

23. FROST, W.H. Epidemiology. In: Maxcy, K.F., org. Papers of Wade Hampton Frust: a contribution to epidemiolog. ical method. New York, Commonwealth Fund., 1941. p. 493-542.

24. GIANNOTTI, J.A. Trabalho e reflexâo: ensaios para une dialética da sociabilidade. São Paulo, Ed. Brasiliense, 1984.
25. GOLDBERG, M. Este obscuro objeto da epidemiologia. In: Costa, D.C., org. Epidemiologia: teoria e objeto. São Paulo, Ed. Hucitec-Abrasco, 1990. p. 87-136.

26. HABERMAS, J. Mudança estrutural da esfera pública: investigação quanto a uma categoria da sociedade burguesa. Rio de Janeiro, Tempo Brasileiro, 1984.

27. HABERMAS, J. Técnica e ciência como ideologia. Lisboa, Ediçőes 70, 1987.

28. HIPOCRATES. Aires, aguas y lugares. In: Buck, C.; Llopis, A.; Nájera, E.; Terris, M. El desafio de la epidemiologia: problemas y lecturas seleccionadas. Washington, Organización Panamericana de la Salud, 1988. p. 18-19. (OPAS - Publ. Cient. 505).

29. HUME, D. Investigação sobre o entendimento humano. Lisboa, Ediçes 70, 1989.

30. KOYRE, A. Do mundo fechado ao universo infinito. Rio de Janeiro, Ed. Forense-Universitária, 1986.

31. LAURELL, A. C. Algunos problemas teóricos y conceptuales de la epidemiología social. Rev. Centroamer. Cienc. Salud, 6: 79-87, 1977.

32. LILIENFELD, D. E. The greening of epidemiology: sanitary physicians and the London Epidemiological Society. Bull. Hist. Med., 52: 503-28, 1979.

33. LIIIENFELD, D. E. \& LILIENFELD, A. M. Epidemiology: a retrospective study. Am.J. Epidemiol., 106: 445$59,1977$.

34. LIND, J. Una investigación sobre la naturaleza, las causas, y la curación del escorbuto. In: Buck, C.; Llopis, A.; Nájera, E.; Terris, M. El desafio de la epidemiologia problemas y lecturas seleccionadas. Washington, Organización Panamericana de la Salud, 1988. p. 20-4. (OPAS - Publ. Cient. 505).

35. LUZ, M. T. Natural, racional, social: razäo médica e racionalidade cientifica moderna. Rio de Janeiro, Ed. Campus, 1988.

36. MACMAHON, B. \& PUGH, T. F. Princípios y métodos de epidemiología. México, La Prensa Médica Mexicana, 1975.

37. MARCUSE, H. A ideologia da sociedade industrial. Rio de Janeiro, Ed. Zahar, 1967.

38. MARX, K. \& ENGELS, F. A ideologia alemä. São Paulo, Ed. Hucitec, 1986.

39. MENDES GONÇALVES, R. B. Reflexōes sobre a articulação entre a investigação epidemiológica e a prática médica a propósito das doenças crônicas e degeneratjvas. In: Costa, D. C., org. Epidemiologia: teoria e objeto. Såo Paulo, Ed. Hucitec/Abrasco, 1990. p. 39-86.

40. MENDES GONÇALVES, R. B. Contribuiç̧ão à discussão sobre as relaçōes entre teoria, objeto e método em epidemiologia. In: Congresso Brasileiro de Epidemiologia. 12. Campinas, 1990. Anais, Rio de Janeiro, ABRASCO, 1992. p. 346-361.

41. MIETTANEN, O. S. Theoretical epidemiology: principles of occurence research in medicine. New York, John Wiley, 1985.

42. POSSAS, C. Epidemiologia e sociedade: heterogeneidade estrutural e saúde no Brasil. São Paulo, Ed. Hucitec, 1989.

43. ROTHMAN, K. J. Madern epidemiology. Boston, Litle Brown \& Co., 1986.

44. SENNETT, R. O declinio do homem público: as tiranias da intimidade. São Paulo, Ed. Companhia das Letras, 1989.

45. SIGERIST, H. La filosofia de la higiene. In: Sigerist, H. Historia y sociologia de la medicina. Bogotá. Ed. Guadalupe, 1974. p. 32-39.

46. SILVA, L. J. Consideraçōes acerca dos fundamentos teóricos da explicação em epidemiologia. Rev. Saúde Pública, 19: 377-83, 1985. 
47. SNOW, J. On continous molecular changes, more particularly in their relation to epidemic diseases. Rev. Infect. Dis., 7: 441-7, 1985.

48. SNOW, J. Sobre a maneira da transmissáo da cólera. São Paulo, Ed. Hucitec/ABRASCO, 1990.

49. SUSSER, M. Causal thinking in health sciences - concepts and strategies in epidemiology. New York, Oxford University Press, 1973.

50. TERRIS, M. The scope and methods of epidemiology. $J$. Public Health, 52: 1371-6, 1962.

51. TERRIS, M. Epidemiology and the public health movement. J. Chronic Dis, 52: 1371-6, 1986.

52. VILLERMÉ, L. R. Reseña del estado físico y moral de los obreros de las industrias del algodón, la lana y la seda.
In: Buck, C.; Llopis, A.; Nájera, E.; Terris, M. El desafio de la epidemiologia: problemas y lecturas selec. cionadas. Washington, Organización Panamericana de la Salud, 1988. p. 34-7. (OPAS - Publ. Cient., 505).

53. WHITEHEAD, A. N. A ciência e o mundo moderno. São Paulo, Ed. Brasiliense, 1951.

54. WINSLOW, C. E. A. The conquest of epidemic disease: a chapter in the history of ideas. Princeton, Princeton University Press, 1943.

Recebido para publicação em 31.7.1992

Reapresentado em 30.2 .1993 Aprovado para publicaçäo em 29.3.1993 